Behavior and Social Issues, 25, 77-98 (2016). (C) Carolyn Brayko, Ramona Houmanfar, \& Elizabeth Ghezzi. Readers of this article may copy it without the copyright owner's permission, if the author and publisher are acknowledged in the copy and the copy is used for educational, not-for-profit purposes. doi: 10.5210/bsi.v.25i0.6739

\title{
Organized Cooperation: A Behavioral Perspective ON VOLUNTEERISM
}

\author{
Carolyn A. Brayko ${ }^{1}$ \\ Ramona A. Houmanfar \\ Elizabeth L. Ghezzi \\ University of Nevada-Reno
}

\begin{abstract}
In 2014 in the United States, an estimated 62.8 million people, or $25.3 \%$ of the population volunteered their time and money to a nonprofit organization, spending around 7.9 billion hours of volunteer time ("Volunteering in 2014," 2015). Volunteerism accounts for a significant portion of the workforce, particularly among nonprofit organizations that rely heavily on community support to provide necessary, yet usually unprofitable services. Despite the importance of volunteer practices, volunteer retention is a pervasive issue and can be a time-consuming and costly endeavor for the organization. The current paper provides a review of behavior analytic literature to discuss how behavior science is suited for empirically investigating the origins and maintenance of volunteer behavior. Furthermore, although behavior systems analysis has not specifically addressed volunteerism, this analytic approach could be beneficial to investigate ameliorating volunteer retention on the large scale. The conclusion explores research suggestions and likely implications of expanding behavior analysis further into this domain.

KEYWORDS: volunteerism, cooperation, altruism, units of analysis, behavior analysis, behavioral systems analysis, macrocontingency, metacontingency
\end{abstract}

There is no shortage of societal ills. Anyone can look around their cultural environment and find social issues jeopardizing the quality of life for either themselves, those around them, or those to come. To name one example in the United States, the care and support of our nation's youth is a constant struggle. In 2013, 20\% of all children (0-17 years old) lived in poverty (Federal Interagency Forum on Child and Family Statistics, 2015, p. 14), and among those living in poverty, $46 \%$ of households were classified as "food insecure" (p. 17). In 2014, nearly one quarter (24\%) of U.S. $12^{\text {th }}$ grade students reported illicit drug use in the past 30 days (p. 43). In a recent international student assessment study, $17 \%$ and $26 \%$ of 15 year olds in the U.S. did not meet baseline proficiency in reading and math literacy, respectively ("Selected Findings from PISA 2012", n.d.). While some of these trends are declining, the numbers are fairly stable from year to year. Clearly, there is a strong need to support at-risk youth to develop skills to navigate an unstable, and sometimes unforgiving, social system. Thankfully, many dedicated institutions and individual volunteers have committed themselves to improving these statistics.

Volunteers annually donate thousands of hours, worth millions of dollars, to the American workforce to benefit local communities at virtually no cost. Through the dedication of volunteers, government and nonprofit agencies continually provide unprofitable, yet needed social services to

${ }^{1}$ Correspondence may be addressed to cabrayko@gmail.com. 
economically distressed populations. For example, Big Brothers Big Sisters (BBBS) is an international organization that relies on the efforts of its volunteers to support and serve as mentors to at-risk youth in their respective communities. These services would likely not exist without the donation of time and money from volunteers. The scale of the financial contribution is staggering. In a 2013 summary of nonprofit data, 1.4 million nonprofit organizations registered with the IRS; and in 2014 over $\$ 358$ billion was donated by individuals and households (McKeever, 2015). In 2014, roughly $25.3 \%$ of residents volunteered their time resulting in 8.7 billion hours of service estimating around $\$ 179.2$ billion worth of service (McKeever, 2015).

Volunteering has also been shown to contribute to the overall health of a community and its members. Articles in social work and social psychology journals discuss the putative impact of volunteering on individuals and their community (e.g., Brown, Nesse, Vinokur, \& Smith, 2003; Harlow \& Cantor, 1996; Post, 2005, to name a few). These reports cite a variety of benefits to the volunteers, such as increased life satisfaction (Harlow \& Cantor, 1996), decreased mortality (Brown, et al., 2003), and better mental and physical health (Post, 2005). In a 2012 report presented at the National Conference on Citizenship, the density of nonprofit organizations within a community was found to be negatively related with unemployment rates (Kawashima-Ginsberg, Lim, \& Levine, 2012). The negative correlation is in part due to the larger nonprofits who are also significant employers in their communities (e.g., universities, healthcare institutions); however, considering that $85 \%$ of U.S. nonprofits have no employees (Gross \& Page, 2013), the impact of volunteerism in a community is detectable. Given the individual and community benefits of volunteer activity, supporting and maintaining volunteers within our local and national organizations is an important factor when considering community well-being.

Focusing primarily on the majority of volunteer-dependent nonprofits, it becomes apparent that continued success is a delicate balance. Despite the benefits to society and massive contributions to the American economy, many nonprofits struggle to stay fiscally solvent, meet demands, and keep volunteers engaged. According to the 2015 State of the Nonprofit Sector Survey by the Nonprofit Finance Fund, 53\% of respondents reported that their nonprofit agency had three months or less of available cash, and 32\% indicated "achieving long-term financial sustainability" as one of the top challenges for their organization ("State of the sector surveys," 2015). Additionally, since the 2008 recession, the majority of respondents $(76 \%)$ reported an increased demand for services, and $52 \%$ of the agencies admitted that they are unable to meet the demand.

One contributing factor to the financial challenges of these nonprofit organizations is the loss of volunteer resources. An estimated $\$ 38$ billion is lost annually due to volunteer attrition (Eisner, Grimm, \& Maynard, 2009). The cost of the volunteer can be estimated by both the cost to the organization to train the volunteer as well as the market value of the service performed. According to the Independent Sector, the average value of non-agricultural, non-managerial work for 2015 is $\$ 23.56$ per hour ("The Value of Volunteer Time," 2016). Furthermore, if the volunteer performs skilled or specialized work (e.g., accounting, IT services), the value of that volunteer increases dramatically. Although volunteers are unpaid, nonprofits spend funds on the training, maintenance, and recognition of volunteers. For example, BBBS reports that setting up a "Match" between a youth and mentor costs an average of $\$ 1,000$ in the first year. Every year the Match between the youth and mentor is sustained, the annual cost to BBBS significantly decreases. Thus, losing trained volunteers comes at a significant cost to a nonprofit organization. From 2005 to 2006, roughly one-third (about 20.9 million) of the nation's volunteers did not return ("Volunteer Retention", 2007). Other reviews have noted an increasing trend of episodic volunteering, where 
people volunteer for brief, intermittent periods (Hyde, Dunn, Scuffham, \& Chambers, 2014). There are many factors contributing to why a volunteer decides to participate or not, but the aforementioned reports highlight the importance of effective management (Eisner, Grimm, \& Maynard, 2009). For example, Eisner and colleagues report that only a quarter of nonprofits regularly provide volunteers with "training and professional development," only $35 \%$ of nonprofits regularly "recogniz[e] the contributions of volunteers," and less than half $(45 \%)$ match "volunteers' skills with appropriate assignments" (p. 34). Behavior science has repeatedly shown the effectiveness of training, positive social reinforcement, and tasking individuals with activities within their fluent behavioral repertoires. Behavior analysts have the research to support best practices in organizations. Creating opportunities for collaboration could lead to optimization of volunteer resources for invaluable social change.

The challenge of promoting volunteerism in organizations provides an opportunity for behavior analysts to apply behavioral principles to create positive social change on both the individual and social level. Doing so fits well within the pragmatic foundations of behavior analysis (Hayes \& Brownstein, 1986; Hayes, Hayes, \& Reese, 1988), and the social values many behavior analysts have historically described (Baer, Wolf, \& Risley, 1968; Dickinson, 2000; Holland, 1978). Despite the importance of studying volunteerism, there is little behavior analytic literature to discuss this practice, potentially due to philosophical and conceptual issues surrounding its altruistic and sociological ties.

This paper aims to discuss how volunteerism can be studied within the field of behavior analysis and elucidate the possible perspectives the field can take to develop a comprehensive and scientific understanding of volunteering behavior origins and maintenance. The first section begins with a brief overview of how volunteerism is discussed in other fields. The discussion then transitions to the relevant units of behavior at both the individual and group levels of analysis, finishing with a suggested behavioral definition of volunteering. A review of the current behavior analytic literature follows as it applies to the function of individual volunteer behavior. Then, we describe how organizations utilizing volunteers function as a behavioral system and how behavior analysts have the opportunity to serve as cultural engineers. The discussion concludes with future research suggestions and various implications as a result of expanding behavior science to this domain. To better illustrate the conceptual account of volunteer behavior, we use the nonprofit organization, Big Brothers Big Sisters (BBBS) as an example.

\section{Survey of Volunteerism outside of Behavior Analysis}

Building a program of volunteer research from a behavior analytic perspective will come with challenges. While behavior analysts have written on volunteer training (Howard \& Digennaro Reed, 2014, 2015), and sometimes mention volunteering in their conceptual papers (Hayes, Bunting, Herbst, Bond, \& Barnes-Holmes, 2006), volunteerism as its own domain for behavior analysis has been largely neglected. The same is not the case in other fields. Volunteer management has generated discussions throughout many fields including applied psychology (Boezeman \& Ellemers, 2008), consumer psychology (Mowen \& Sujan, 2005), organizational psychology (Vantilborgh et al., 2011), social psychology (Clary et al., 1998; Cornelis, Van Hiel, \& De Cremer, 2013; McBride \& Lee, 2011; Nenga, 2012; Thoits \& Hewitt, 2001), economics (Govekar \& Govekar, 2002; Lee \& Brudney, 2012), marketing (Randle \& Dolnicar, 2011; Starnes \& Wymer Jr, 2000), as well as what seem to be interdisciplinary fields dealing directly with the study of nonprofits and volunteerism (Farmer \& Fedor, 1999; Liao-Troth, 2005; Nichols, 2012; 
Shye, 2009). Before diving into a new analysis of volunteerism from a behavior analytic perspective, some recognition should be paid to the valuable work done outside the field.

Despite the diversity of fields represented in the volunteerism literature, there is a generally consistent view of what constitutes volunteer activity. Some focus on the agency of the volunteer in that they specify that volunteering is purposive (Brennan, 2007), subject to free will (Cornelis et al., 2013; Thoits \& Hewitt, 2001; Vantilborgh et al., 2011), and cannot be compelled (Bandura \& Lyons, 2012). Others specify beneficence as a key aspect of volunteerism (Cornelis et al., 2013; Han \& Hong, 2012; Mowen \& Sujan, 2005; Vantilborgh et al., 2011). A third noticeable trend is the appeal to unpaid work (Ganesh \& McAllum, 2011; Lee \& Brudney, 2012; Starnes \& Wymer Jr, 2000). Snyder and Omoto (2008) provide a comprehensive treatment of the definition of volunteerism, in which they state that volunteerism: (1) occurs based on the individual's "free will" and not due to coercion, (2) deliberately serves others, (3) occurs as a pattern over time, (4) is based "on the person's own goals without expectation of reward or punishment," (5) serves a population or cause that acknowledges and asks for help, and (6) commonly occurs through an organized agency (p. 2). Much of the Snyder and Omoto definition fits well within a behavioral framework, barring the purposive language (e.g., "without expectation of reward"), which serves to lay a foundation for behavior scientific research.

Within the volunteerism literature exists the "functionalist approach" which will provide familiarity for behavior analysts who do not recognize free will as a scientific explanation for motivation. The functionalist perspective "focuses on individual motivations for helping" (Finkelstein, 2008, p. 10). Snyder and Omoto (2008) refer to the functional analysis as an approach that "emphasizes the purposes served by action and the role of such purposes in initiating, guiding, and sustaining action" (p. 11). For example, Snyder and Omoto describe their Volunteer Process Model, which accounts for antecedents, immediate consequences (to which they refer as "experiences"), and cumulative consequences (to which they refer as "consequences") both at the individual and the behavioral systems levels. Regardless of one's philosophical position on causality and purpose, the functional orientation in volunteer literature fits well within the empirical analysis of behavior which also emphasizes the function of behaviors based on environmental conditions and relevant consequences. The existing functional volunteer literature sets up a launching point for any behaviorist to make meaningful contributions to this elaborate body of work.

As an interdisciplinary endeavor, care needs to be taken to avoid repeating the good work that has already been done in other fields. The aforementioned literature on volunteerism and volunteer management is just a small sample of the ocean of conceptual and empirical articles available. Behavior analysts, with a pragmatic scientific goal and commitment to lawful principles of nature, can play a special role in participating in this discussion. Currently, the discussed antecedents in non-behavior analytic research include personality traits, demographic variables, and what are commonly referred to as "motivational" variables. Many of these factors are made inaccessible by defining them as private, or subject to free will, and others are elaborate interpretations of the role of verbal behavior as it applies to volunteering. Behavior analysis seeks variables that can be manipulated in order to predict and control behavior. For example, behavior scientists have difficulty with definitions of behavior as requiring no consequence, such as in Snyder and Omoto's (2008) definition wherein they claim volunteering to be based "on the person's own goals without expectation of reward or punishment" (p. 2). Claiming that behavior maintenance is beyond the realm of contingency management leaves little space for the behavioral engineer to intervene, thus we will adopt a perspective of volunteering that is subject to environmental antecedents and 


\section{ORGANIZED COOPERATION}

consequences. Another example of a somewhat inaccessible variable is empathy, as it relates to impacting volunteer behavior (Stürmer, Snyder, Kropp, \& Siem, 2006; Stürmer, Snyder, \& Omoto, 2005). Work has been done to establish empathy as a variable of importance, however there is less said regarding the conditions under which empathy is learned. This is the stuff of behavior analysis. Training behavioral components, like perspective taking (Houmanfar \& Ward, 2012), could be a missing link for recruiting and retaining volunteers.

For the remainder of the paper we will focus on how behavior analysts could approach volunteer behavior. First, the units and relevant controlling factors are considered, followed by a conceptual analysis of volunteerism at both the individual and systems levels. Within the discussion, we address the role of verbal behavior, specifically rule-governed behavior, as a vehicle for connecting the interdisciplinary models with behavioral principles.

\section{Units of Analysis for Studying Volunteerism}

When exploring a new area, identifying appropriate units of analysis directly impacts the integrity, generalizability, and external validity of the data produced with respect to their generalizability to the events as they occur naturally. Thompson and Lubinski (1986) eloquently describe the importance of carefully setting the parameters on complex behavioral events: "it follows that the way continuous behavioral repertoires are divided into fundamental units is critically important in determining the success of the entire scientific study of behavior" (p. 220). Both behavior analysis and behavioral systems analysis provide units that suitably address volunteer behavior at both the individual and group levels. Utilizing functional units in researching volunteer behavior at the individual and systemic levels has pragmatic value for the nonprofit agencies, policy makers, and other consumers interested in using scientific results to inform their decisions. This section will suggest an analysis of the volunteer event as a measurable unit and explore how volunteerism can be examined based on a functional definition.

Before suggesting some perspectives on volunteering, note that ultimately these parameters "must be shown empirically" (Thompson \& Lubinski, 1986, p. 220). Defining the behavioral event based on topographical features loses the functional element, and may eventually prove ineffective. Thompson and Lubinski suggest that complex behavior is likely to fit within a combination of functional response classes and functions. Higher order reinforcement schedules likely play a role (i.e., multiply controlled behavior on multiple, concurrent schedules). That is to say, studying a complex pattern of behavior, volunteering, cannot be examined with unidimensional analyses. Experimental investigation will ultimately determine this notion, but it is reasonable to expect that when individuals volunteer, their behavior is not solely controlled by one particular reinforcer on one isolated intermittent schedule. As such, the reader should first exercise caution when reading this conceptual account of volunteer behavior, and recognize the need for experimental work.

Several factors need to be considered when identifying the parameters of a volunteer event. Defining volunteering as "unpaid work," as some have, fails to account for examples of prosocial activity that would not meet the common-sense criteria. While performing civic duties like jury duty or stopping at an occupied crosswalk are unpaid and service for the good of others, there are multiple legal contingencies maintaining that behavior. Philanthropic activity, too, although similar to volunteering, does not require the commensurate response cost. Donating money to a cause is presumably prosocial, but not necessarily an ongoing activity typically thought of as volunteer work. Regardless of what it may look like, volunteer behavior is generally accepted as 
action occurring outside of formal governmental contingencies and implies some time and effort spent.

Even excluding civic obligations and donations, volunteering can still take many forms. The topography of volunteer behavior varies depending on the context (e.g., culture, learning history, establishing operations) and the function (e.g., tangible, social, verbal) of that behavior. Volunteer behavior can be a solitary event (e.g., organizing a meal train for a family experiencing a recent loss) or could reflect a pattern of behavior (e.g., weekly mentoring through BBBS). In considering the aforementioned features of a volunteer event, a suggested behavioral definition of volunteering is any ongoing human behavior reinforced by improving the reinforcing conditions for others, outside of personal relationships, professional responsibilities and civic duties.

On the individual level of analysis of volunteer behavior, the behavioral unit fits into the threeterm contingency. The antecedent conditions that set the occasion for this operant response remain to be tested empirically; however, one may hypothesize that both general and specific factors influence volunteerism. Generally, the volunteer has a learning history in which positive social attention often follows volunteer behavior. Specific to the immediate volunteer event, establishing operations, such as deprivation of social attention (positive reinforcement) or a request made by a respected peer (negative reinforcement; e.g., to avoid judgment) could be responsible for evoking volunteer behavior. Other socially-mediated factors, such as modeling, may set the occasion for others to volunteer, in that seeing others contacting reinforcement for volunteering might make it more likely for the observer to volunteer in the future. Depending on the social and organizational context in which the individual volunteers, a number of positive and negative reinforcers are at work. Social praise, public recognition, and tokens for participation are all common examples of positive consequences for volunteering. For example, when volunteering for BBBS, public recognition is likely when Bigs, the mentors, are out with their Littles, in addition to seeing Littles explore new opportunities and contact new reinforcing conditions. Using units like the three-term contingency work best to describe the conditions under which individuals learn and maintain volunteer behavior.

At the systemic level, volunteer events could be examined as existing within both macrocontingencies and metacontingencies, the major units discussed in behavioral systems analysis. Malott and Glenn (2006) define a macrocontingency as, "the relation between the operant lineages of all people engaged in the cultural practice and the aggregate product" (p. 37). With a macrocontingency, the behavior analyst can evaluate how many individuals across organizations and cultures may be engaging in the same behaviors, despite separate functions and contingencies. For example, when many people mentor through BBBS, regardless of the conditions under which they volunteer, their volunteered time with their Littles have a measurable and cumulative impact on a societal scale.

The metacontingency as Malott and Glenn (2006) describe involves "contingent relations analogous to those in a [sic] operant contingency and it contains many operant contingencies within itself" (p. 38). The metacontingency relies on the notion of multiple individuals acting in an interlocked manner producing an aggregate product. The key feature of this unit is that "the recurring interrelations are due to operant contingencies in which the behavior of some people repeatedly function as the environment in the operant contingencies maintaining the behaviors of others" (p. 38). Using the metacontingency describes how one could assess individual impact on other's performance and how that interaction impacts the larger system (e.g., management practices, communication networks). 


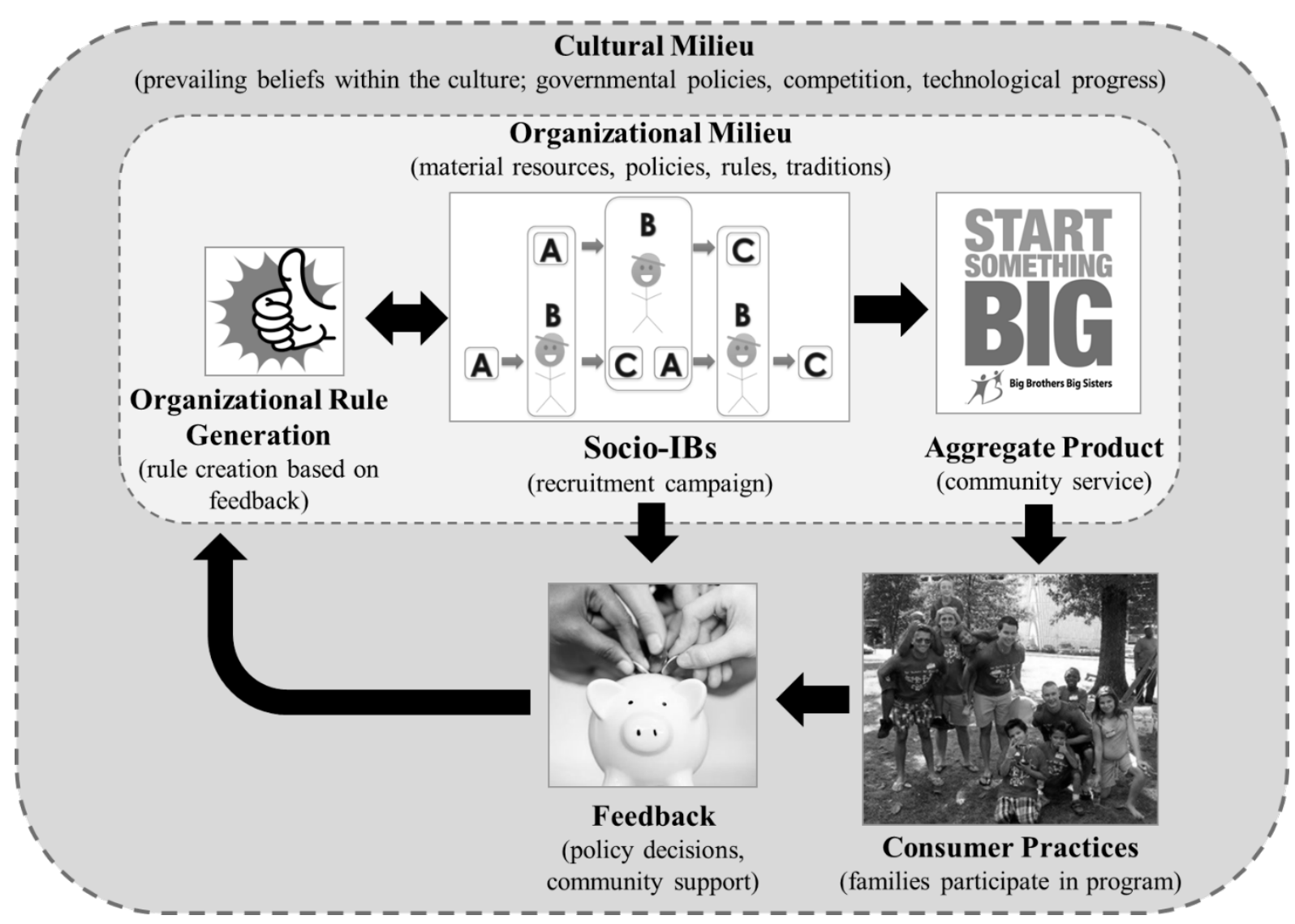

Figure 1: The five-term metacontingency (Houmanfar, Rodrigues, \& Ward, 2010) is a useful unit of analysis for assessing how groups of individuals behave with each other within a cultural context, or milieu. When running effectively, the metacontingency works as an elaborate feedback loop. When running poorly, this model identifies where the breakdown may be occurring, which in turn pinpoints where and how to intervene.

BBBS as a nonprofit organization is a part of a metacontingency, as shown in Figure 1. At the top of the figure, the "Socio-IBs" refer to the interlocking behaviors (i.e., where the consequence of one person's behavior acts as the antecedent for another person's behavior) of BBBS recruiting new Bigs and Littles. The BBBS employees interact with the Bigs, the Littles, and the Littles' families. If effective, the socio-IBs produce effective mentoring, and increase positive opportunities for impoverished children (i.e., the aggregate product). The more successful the aggregate product, the more visible the impact. This creates opportunities for communities to begin or continue supporting BBBS (which includes both Bigs and Littles). Consumer practices such as participating in the BBBS programs can be considered the macrocontingency of volunteering, contributing to the cumulative impact of volunteer services on the societal level. It is then through changes in donations, participation in fundraising events, and other outcomes that BBBS receives feedback which can alter both the initial interlocking behavioral contingencies for recruitment and how the organization continues to develop policies and strategies for growth. The process wherein organizational rules shape the Socio-IBs that produce the aggregate product is informed by the context of the organizational milieu" (Houmanfar, Rodgrigues, and Ward, 2010). 
The metacontingency framework also takes into account the cultural milieu which sets the occasion for the metacontingency to be selected within the larger context (Houmanfar \& Rodrigues, 2006). That is, using the ongoing example, the BBBS metacontingency operates and adapts based on what appropriate interventions and mentorship looks like in the region in which it operates. The more successfully BBBS functions at the metacontingency level, the more likely it will survive and flourish as a feature of larger cultural practices. The fact that BBBS has existed for more than 100 years in the United States suggests that its contribution to society is useful, effective, and appreciated. Using the macro- and metacontingency units becomes especially important when the desired outcome is large-scale change.

Having identified the parameters of investigative units, we will discuss the controlling factors responsible for volunteering on an individual and behavioral systemic level. The following sections suggest possible analyses for both levels given the current behavioral literature.

\section{A Behavior Analytic Account of Volunteerism}

The function of volunteer behavior is likely to be multiply controlled and maintained by a combination of verbal and social means. This section explores how related behavior analytic literature on cooperation, altruism, and contemporary theories of verbal behavior contribute to the conceptualization of volunteerism.

\section{Volunteerism as Cooperation}

Cooperation serves as a parsimonious explanation for volunteer behavior. It must be noted that the concept of cooperation is rarely specifically defined, nor is there much coherence among the definitions in the published literature (Guerin, 1994). Cooperation is generally conceived as behavior that collectively benefits the individual and the group. Or, as Skinner (1953/1965) described it, "the reinforcement of two or more individuals depends upon the behavior of both or all of them" (p. 311). Keller and Schoenfeld (1950) coined the earliest behavioral definition: where "the combined behavior of two or more organisms is needed to procure positive, or remove negative, reinforcement for either" (p. 357). The variations of these definitions all include the concurrent behavior of multiple individuals wherein a consequence is shared collectively; which Skinner summarizes concisely. As such, this paper will default to Skinner's definition of cooperation to analyze the class of behaviors known as "volunteering."

Both the colloquial conception of volunteerism and volunteer studies align with the behavioral definition of cooperation. As previously mentioned, volunteering benefits the volunteer as well as the community (Brown \& Ferris, 2007; Brown et al., 2003; Harlow \& Cantor, 1996; Post, 2005; Thoits \& Hewitt, 2001), which seems to fit the behavioral account of cooperation. The relationship between the Big and the Little, referred to as a Match, is the basis for successful volunteer efforts within this particular non-profit organization. In addition to highlighting the numerous benefits for Littles resulting from a quality Match, BBBS lists the benefits Bigs can also expect. From providing "an excuse to do kid things again, like go to animated movies and ride go-carts," to "networking," to "the chance to make a difference," Bigs have the opportunity to contact reinforcement while arranging positively reinforcing conditions for their Littles ("The Benefits of Mentoring," 2012). In addition to contacting immediate positive reinforcement while being together as a Match, the longer and the higher quality the Match, the more the benefits accumulate over time to improve the lives of both parties. 
Just as volunteerism can be conceptualized as cooperation, it can also be studied empirically with similar measures and procedures accepted in the cooperation literature. Cooperation has been discussed in behavior analysis, and typically quantified and measured according to the prisoner's dilemma game, which is a metaphorical situation to evaluate one's tendency to work for personal gain or mutual gain (Jones \& Rachlin, 2009; Locey, Jones, \& Rachlin, 2011; Locey, Safin, \& Rachlin, 2013; Rachlin, 2002; Rachlin \& Locey, 2011). In the prisoner's dilemma game, two individuals have two alternatives: to cooperate or defect. These two choices can create three results: high payout, no payout, or a moderate payout. In a one-time play of the prisoner's dilemma game, defecting results in the highest individual payout, provided that the other player selects the "cooperate" option, in which case the cooperator gets no payout. Over multiple trials, however, the highest payout for both parties is to continually select the cooperate option.

The results of these types of studies show that individuals are more likely to cooperate in situations that are eventually rewarded, perhaps at the expense of immediate individual rewards. Similar delayed consequences are observed in terms of volunteering. While a single outing of a Big with a Little may produce a small, temporary impact, regular activity for a prolonged period will produce cumulative positive effects, such as lasting behavior change in the Little (i.e., attending school more often, valuing education more, avoiding risky behaviors like drug and alcohol use). When the Big dedicates time to the Match, seeing visible improvement in their Little's academic and personal lives can be a powerfully reinforcing consequence.

Having a quantitative measure for cooperation for a simple choice task is helpful to investigate the conditions under which individuals cooperate. Using the empirical work already conducted, like with the prisoner's dilemma game, is a potential launching point for studying volunteerism. If it is the case that prolonged exposure to a social group promotes cooperative behavior, similar procedures could be adopted to investigate the role of social contingencies on volunteer retention.

Despite the behavioral work that has been done on cooperation, classic tasks like the prisoner's dilemma game do not fully capture the complex variables involved with volunteer behavior. The limited nature of the task and the extensive work done on it may also suggest that more should be done to create newer, more complex models for studying and understanding volunteerism. In particular, volunteer activity generally occurs without any programmed, tangible reinforcer. To enhance external validity of future cooperation studies, behavior analysts would do well to include more elaborate procedures utilizing more naturalistic contingencies.

\section{Volunteerism as Altruism}

Altruism is another potential framework to analyze volunteerism. Behavior analysts have explored this concept despite the potential barriers many scientists have with the notion of "altruism." Traditionally, altruism is defined as "behavior by an animal that is not beneficial to or may be harmful to itself but that benefits others of its species" ("Altruism", n.d.). A deterministic scientist would reject an explanation of altruistic behavior in terms of free will, and functionally speaking, behavior analysts would object to persistent behavior in the absence of reinforcement, if not the presence of highly punishing consequences. As such, the altruistic phenomenon can appear more like folklore than science.

Rachlin (2002) frames altruism in a way that can be studied empirically, without assuming supernatural entities. He states that "a truly altruistic act is always part of a pattern of acts (highly valued by both the actor and the community) particular components of which are dispreferred by the actor to their immediate alternatives" (p. 244). As he describes it, altruism consists of not a 
single act, but a pattern of behaviors that occurs under three specific conditions. When comparing a larger "whole" activity with a smaller "brief" activity, altruism occurs when the individual selects the whole activity under the following conditions: 1) the whole activity is preferred to a certain number of occurrences of the brief activity, 2) the brief activity is preferred to a fraction of the whole activity, and 3) a group benefits from the engagement with the whole activity, rather than the brief activity. Put in a volunteering example, Rachlin would call volunteering altruistic based on his three factors: 1) over a long time, the sum of volunteering would be preferred over the sum of shorter, easier, potentially more enjoyable activities (e.g., staying home, watching TV), 2) over a short amount of time, watching TV would be preferred over sustained volunteering, and 3) a community would benefit from volunteering over time, but not from staying home and watching TV. Rachlin's conditions for altruism are based on the philosophy that under certain situations the whole produces a more reinforcing consequence (i.e., teleological behaviorism). Rather than accepting that altruism lacks a reinforcing consequence, Rachlin indicates that the reinforcing value of altruistic acts, "is obtained only when such acts are grouped in patterns that are, as a whole, intrinsically valuable" (p. 244).

It is possible to conceive of volunteerism as working within the altruism construct, in that the larger, longer, less immediately reinforcing activity benefits a group and may be preferred by the individual over a smaller, briefer activity that may not result in the same social outcome. Like Rachlin's description, volunteerism is more likely to be a pattern of behavior, acting for the good of the group, in which a history of volunteering and acting consistently with social values provides the context for future volunteer actions to be reinforced. For example, one instance of working with a child at BBBS is not likely to produce much impact for either the Little or the Big; however, repeated outings are more likely to produce visible outcomes in the child's life and would more likely be supported and praised by the community.

Researchers interested in applying the methodologies from the altruism literature will find a wealth of information in delay and social discounting research. Rachlin and colleagues have set the precedent to study altruism within the delay discounting paradigm (Jones \& Rachlin, 2009; Rachlin, 2002a; Rachlin \& Jones, 2008; Rachlin \& Locey, 2011; Yi, Charlton, Porter, Carter, \& Bickel, 2011). Social discounting "measures the value to a person of a reward to another person at a given social distance" (Jones \& Rachlin, 2009, p.191). Social discounting has been demonstrated in many studies by using a public goods game. A public goods game requires all participants to cooperate in order for the outcome to have the greatest benefit to the group. For example, a group of people are each given $\$ 10$ dollars and are told they can contribute any part of that money to the group. Whatever contributions made by each individual to the group pool will be doubled and equally distributed back to the group, regardless of their contribution. The most utilitarian option is that all participants will contribute their entire amount, as that will yield the largest reward for the entire group. However, by choosing to keep the $\$ 10$, the participant will still receive money back if others choose to contribute to the pool. It is important to note that anonymity, group size, and contextual factors are all variables to consider when observing the conditions under which people behave with respect to social discounting (Jones \& Rachlin, 2009). Therefore, rather than viewing altruism as a dichotomous variable, delayed discounting procedures allow the investigator to study the degree to which individuals select altruistic options under certain conditions.

Empirically, volunteerism could also be studied using delay and social discounting methodologies. For example, using similar choice procedures, one could assess one's willingness to volunteer by asking participants to hypothetically donate different durations of time to a particular cause. Potentially such measures may correlate with volunteer maintenance. Similar to 


\section{ORGANIZED COOPERATION}

the weakness of the prisoner's dilemma game, however, these procedures do not help us understand the conditions under which volunteer behavior maintains. Developing a methodology for setting the occasion for altruistic behavior to occur, if possible, would greatly advance not only behavior science but also mainstream understanding of selfless acts.

In short, cooperation and altruism may contribute to future research in the volunteerism literature, but the methodologies developed in these areas do not fully overlap with the main focus of articles on volunteering. Investigators have already identified "values," "esteem enhancement," and "agendas for action," to name just a few, as primary functions for volunteer behavior (Snyder $\&$ Omoto, 2008). From a behavior analytic perspective, these factors would be evaluated as verbal stimuli and verbal behavior. Since the behavioral accounts of cooperation and altruism have not yet provided empirical analyses of verbal behavior within their frameworks, we will briefly review how verbal behavior, specifically rule-governed behavior, plays a role in developing and maintaining the volunteer repertoire.

\section{The Role of Verbal Behavior}

While some make the case that cooperative and altruistic acts occur among non-human species (Burkart, Fehr, Efferson, \& van Schaik, 2007; Clutton-Brock, 2009), volunteering is a uniquely human activity, implying that verbal behavior plays a significant role in repertoire development and maintenance of elaborate prosocial and cooperative behaviors in humans (Hayes \& Sanford, 2014). As previously discussed, volunteering rarely results in achieving the end goal, earning rewards, or even social recognition. Verbal behavior is, in many instances, governed by rules, both explicit and implicit. Rule-governed behavior may be able to explain the conditions under which individuals volunteer when no direct-acting contingencies are apparent. For example, an individual might generate the implicit rule, "If I volunteer, I am a good person." Therefore, the consequence of volunteering is being a good person, which reinforces the rule follower's volunteer behavior.

In addition to rule-governed behavior, relational responding can explain one's history of responding to certain verbal stimuli. Relational responding involves the relation between two (or more) stimuli in arbitrary ways (Mattaini, 2013). Though the word, "volunteer" has no inherent connection to the behavior of volunteering, the relationship between the two has been established by language. This relationship is called an "equivalence relation" and in most cases involves words, concepts, conditions, and entities. To expand our example, perhaps the word "volunteer" is in a relation with the concept of "good." Given that the word "volunteer" is already associated with the behavior, volunteering is now associated with "good." The three stimuli are now in a relational network with each other (Mattaini, 2013). Relational responding based on arbitrary equivalence relations is one of the foundational components of Relational Frame Theory.

Relational Frame Theory (RFT) can begin to explain the acquisition and maintenance of volunteer behavior when more traditionally conceived reinforcers are not immediately present. The distinct advantage of taking an RFT approach is that it allows for a fully functional account of verbal behavior for both the speaker and listener, and affords experimental analysis of verbal behavior to a greater degree than the Skinnerian approach (Hayes, Gifford, \& Hayes, 1998, p. 255). Thus, this paper will analyze the influences of verbal behavior as interpreted through an RFT lens.

Part of RFT posits that verbal stimuli are inherently arbitrary and take on functional stimulus properties given a learning history associated with those stimuli (Hayes et al., 2006; Hayes, 2004; Steele \& Hayes, 1991). Simply put, verbal stimuli can function as reinforcers (via transfer of stimulus function) given a history of those particular verbal stimuli being paired with reinforcing 
consequences. From this perspective we can look at words as a potential verbal reinforcers, which refer to "events that function as reinforcers because of their participation in relational frames" (Hayes, Gifford, \& Hayes, 1998, p. 262). Through transformation of function, the statement on the BBBS website, "By helping children develop supportive relationships with positive role models, we make a direct and lasting impact on their lives," may have reinforcing properties when a person fills out an application to become a Big. Likewise, working with a child at BBBS, Bigs are told, "Littles matched with Bigs are 46\% less likely to use illegal drugs" ("Big impact —Proven results," 2016), which may maintain volunteering even when it becomes inconvenient, and even though they will likely never come into contact with the "lasting" consequence of their efforts.

The issue of morality fits well into the RFT framework, as well. Morality, through a behavioral lens, would not be considered a cause for cooperation or altruism (Soreth, 2011), but perhaps a mediator of verbal behavior. Viewing morality as a subset of cooperation is also consistent outside of behavior analysis (Tomasello \& Vaish, 2013). Hayes, Gifford, and Hayes (1998) discuss the development of moral behavior from the perspective of RFT, which relates to a similar, more contemporary article on the evolution of cooperative behavior as is relates to language and cognition (Hayes \& Sanford, 2014). By reviewing the role of language in cooperative and moral repertoires, a greater understanding about the origins and maintenance of volunteer behavior emerges. Hayes and colleagues offer an in-depth analysis of moral behavior as rule-governed behavior (RGB). In their analysis of moral development, Hayes and colleagues discuss moral behavior based on RFT's three classes of RGB: pliance, tracking, and augmenting. Space precludes a thorough overview of the article; however, the main points will be summarized below with definitions as they pertain to the development of volunteer behavior. Readers interested in a more thorough introduction to rules from an RFT perspective are encouraged to read the original article (Hayes, Gifford, \& Hayes, 1998).

Volunteering functions as pliance if the mediator of the contingency is social, usually a respected person, particularly if that person is in a position of authority. An example of this would be when a boss offers opportunities for employees to engage in extra "voluntary" activities, the colloquial work expression being "voluntold" to do something. Just as Hayes, Gifford, and Hayes (1998) liken moral behavior to tracking, volunteering could be analyzed as a form of tracking, provided that the volunteer activity led the individual to more efficiently contact naturally occurring and available reinforcers. Tracking fits well with many reports on volunteerism, in that volunteer activity correlates with improved health and well-being and increased social support networks.

What seems to fit the best, however, is using the framework of augmentals for understanding the verbal influence on volunteer behavior. The augmental "is most important for the establishment of abstract consequences such as fairness, justice, peace, or righteousness" (Hayes, Gifford, \& Hayes, 1998, p. 262). If people attribute their volunteer behavior to the notion of improving the community, minimizing disparities, or otherwise some sentiment of "giving back," they engage in verbal behavior as a derived verbal relation which enhances the reinforcing value of another otherwise distant and weak reinforcing consequence. To use mentoring as an example, the BBBS organization may tell their volunteers that their mentoring influence could keep their Little off drugs. The event of preventing drug use is a potentially distant consequence, if it even occurs; thus the rule maintains or enhances the reinforcing value of a consequence that is not present.

In continuing to look at volunteerism as being maintained by rule governance, volunteering could also result from values clarification. The term values, as meant here, refers to "a type of rulegoverned behavior that specifies remote consequences and the general behaviors that ultimately 


\section{ORGANIZED COOPERATION}

(the individual presumes) result in contact with those consequences" (Herbst \& Houmanfar, 2009, p. 56). As previously stated, when volunteering for a cause, the consequence is often remote, thus the value statement acts as a formative augmental. Hayes, Bunting, Herbst, Bond, and BarnesHolmes (2006) summarize the act of defining values as, "link[ing] current behavior to desired global qualities of ongoing actions" (p. 16). For example, individuals may value "social justice," and in viewing the social disparities of impoverished families may start mentoring at BBBS as a way to continuously advocate (i.e., ongoing action) for improved well-being for children in poverty (i.e., social justice as a desired global quality).

Although an analysis of an individual's volunteering allows for a more granular account, it is also useful to investigate volunteering within the larger context. The volunteer performs in an engineered environment, arranged specifically to manage multiple volunteers acting in concert with a common goal. When developing interventions that will significantly impact nonprofit agencies and their services, systemic manipulations may be more effective than conducting a functional analysis of volunteering for each individual participant. A systemic perspective provides a higher level of analysis, which may lead to the development of more pragmatic and cost-effective solutions to the issues surrounding volunteer management.

\section{A Behavioral Systems Analysis of Multiple Volunteers}

Although the size of the group may vary, all volunteers belong to a larger system. Unfortunately, as discussed in the introduction, many leaders in organizations underestimate the value of volunteers and how to manage them more effectively (Eisner et al., 2009). Ultimately, this is a systemic issue not a problem with individual volunteers. If the system in which individuals volunteer is not capable of reinforcing the pattern of volunteer behavior, people leave, resources deplete, and the agency bears the burden of understaffed, underpaid workers.

Behavior systems analysis (BSA) has a strong foundation based on the principles of behavior science that would allow organizations to apply evidence-based systemic procedures in order to create nurturing environments necessary for people to thrive. Prosocial leadership and organizational rule generation reinforcing prosocial behaviors are integral factors to consider when evaluating strategies for cultural change (Houmanfar, Alavosius, Morford, Herbst, \& Reimer, 2015). In order to do so, a larger cultural analysis of creating and sustaining prosocial environments is necessary. As Biglan and Glenn (2013) note, the science of BSA is poised to translate its existing knowledge on how to create prosocial environments into widespread cultural benefit.

\section{Volunteerism within the Macrocontingency}

Volunteerism fits within a macrocontingency framework, as described in M. Malott and Glenn (2006). Viewing collective volunteer behaviors within the scope of a macrocontingency may be helpful, if the goal is to take a wider view of social issues and assess the global impact volunteering may have within a culture. Since all volunteers have separately developed their own repertoire with respect to donating their time and money to a larger formalized group, the volunteer repertoire of the individual has an "operant lineage." M. Malott and Glenn state that a macrocontingency "does not imply that the product functions as a consequence that maintains the behavior constituting the practice [...] The individual lineages of the various people can be selected by local contingencies applied to the relevant behavior" (p. 37). From the macrocontingency framework, 
we can better appreciate how the volunteers' aggregate product has a substantial impact on our community.

However, M. Malott and Martinez (2006) comment, "a behavioral contingency is to organizational change like a drop of water is to an ocean" (p. 2). In other words, behavior within a macrocontingency consists of individual behavioral repertoires that are functionally unrelated. Intervening in a way that would change the cumulative product would result in setting contingencies for each individual. The underlying function of volunteering relies on a larger, aggregate goal that can only be achieved by the group of individuals working toward a common outcome. The product of one volunteer at BBBS is the support of one child, which is no doubt meaningful to the volunteer and the child, but has no larger effect. However, the consequence of many volunteers, across many cities, produces a larger aggregate product, which in this case is a generation of supported children. Biglan (2015) shows that the common outcome of this nurtured, aggregate product results in benefits that far exceed the individual.

\section{Volunteerism within the Metacontingency}

Placing coordinated volunteer activity within a metacontingency will better allow for systemic interventions that can be applied at one level and trickle through the organization. Metacontingencies involve interlocking behavioral contingencies, where the consequence of one person's reoccurring behavior serves as the antecedent for another person's reoccurring behavior, within a cultural context (see Figure 1 for an example). Houmanfar and colleagues (2010) suggest three processes of selection within the metacontingency: socio-interlocking behaviors within the organization, aggregate product by the consumer, and effective-group rules by the organization. Effective group rules within the organization requires a communication network in the organization that is clear, unambiguous, and open (Houmanfar \& Johnson, 2004). Explicit, wellestablished rules within the organization set the occasion for interlocking behavioral contingencies that enhance productivity and lead to more accurate self-generated rules (Johnson, Houmanfar, \& Smith, 2010).

At the metacontingency level, due to interlocking behavioral contingencies, it is possible to intervene at one level of the organization, which then sets the occasion for behavior change in individuals who work within that level of the hierarchy but are not directly influenced by the program change. This way one can look at multiple levels of the volunteer system, the interlocking behavioral contingencies necessary for volunteering to take place, and how successful volunteer activity can contribute to the overall aggregate product that is produced to the receiving system (e.g., the public).

Using the perspective of the metacontingency, one can examine volunteers behaving within the context of the nonprofit organization. For example, explicit and accurate feedback from consumers facilitates more effective rule generation within the organization to which volunteers can more effectively respond. When a BBBS supervisor provides feedback to a Big, the Big can then provide higher quality mentorship to the Little. Higher quality mentorship may lead to better Match rapport with a Little. Satisfied families then are more likely to provide positive feedback to the organization. A breakdown within the metacontingency can result in an array of negative consequences such as high turnover rates of Bigs, dissatisfied Littles, and difficulty recruiting new Bigs.

Attempting to establish individual contingencies for people to engage in volunteer behavior is hardly feasible as opposed to changing the organization in which volunteer behavior occurs. 
According to the national survey in 2014 ("Volunteering and Civic Engagement in the United States," 2014), more than 62 million people in the United States volunteer their time to local and national causes. The primary issue with volunteerism then appears to be one of volunteer retention rather than volunteer recruitment. Our culture values participating in nonprofit endeavors, and there are many people willing to participate. By taking a BSA approach, nonprofit agencies could assess their greatest barriers to volunteer retention and arrange proper contingencies to manage employee and volunteer performance alike. By setting up interlocking behavioral contingencies, connecting the paid staff and the volunteers, the organization is more likely to be successful in producing a higher quality, more cost-efficient aggregate product (e.g., supported youth).

\section{Volunteerism within a Cultural Analysis}

There has been a significant amount of theoretical and case study work conducted in creating meaningful change at the larger, cultural level (Biglan, 2009; Biglan \& Glenn, 2013; M. Malott \& Glenn, 2006; M. Malott \& Martinez, 2006; Mattaini, 2013). When looking at current social issues, one may focus on prevention (Biglan, 2003, 2009; Biglan \& Glenn, 2013), or, reinforcing sociallyvalued practices (M. Malott \& Martinez, 2006; Mattaini, 2013). Either way, social and cultural change is inevitable. By employing the work of BSA, it may be possible to arrange the environment in ways that guide positive cultural change more swiftly. One way to arrange the environment to promote positive social change is to create advocacy groups that Mattaini (2015) suggests be, "grounded in behavioral systems science committed to the intentional construction, shaping, and maintenance of behavioral systems dynamics" (p.9).

An important part of the behavioral system is the cultural milieu that provides the context for a metacontingency to occur. The contextual variables may be any number of environmental factors (i.e., laws, policies, traditions, competition). As Houmanfar and Rodrigues (2006) point out, an important factor in analyzing any metacontingency is to look at the first term of that contingency, which is the cultural environment. Consider that there are 3 million children under the age of 6 living in extreme poverty in the United States (Robbins, Stagman, \& Smith, 2012). The cultural milieu, therefore, influences both organizational practices and the reinforcing effectiveness of certain products. This context establishes the demand for organizations like BBBS. Metacontingency is therefore a way to examine organizational processes that respond to cultural selection and have a larger impact on cultural survival and practice. While we look to cultural selection as a means to analyze patterns of consumer and cultural practice, we must examine individual patterns of behavior and the immediate reinforcing consequences within organizational practices. Figure 2 is a model introduced by Mattaini (2013) that highlights the key contextual, structural, and consequential variables associated with recruiting and retaining individual volunteers. The key factors in successfully recruiting and supporting volunteers within an organizational setting include the promotion of prosocial behavior within the cultural setting, the organizational setting, and the individual reinforcing consequences associated with doing so.

Volunteering, like other socially-maintained activities, lacks conspicuous contingencies that shape and maintain the behavior, unless specifically programmed by the institution. Many cultural practices are described by R. Malott (1988) as being shaped by indirect contingencies which are "too delayed, too improbable, or too small, though they may be of cumulative significance" (p. 185). In lieu of more tangible reinforcers that are delivered directly with performance, one's learning history with respect to helping others, and serving an abstract cause, seems to be mediating both social action and volunteerism (Mattaini, 2013). Just like the cultural 


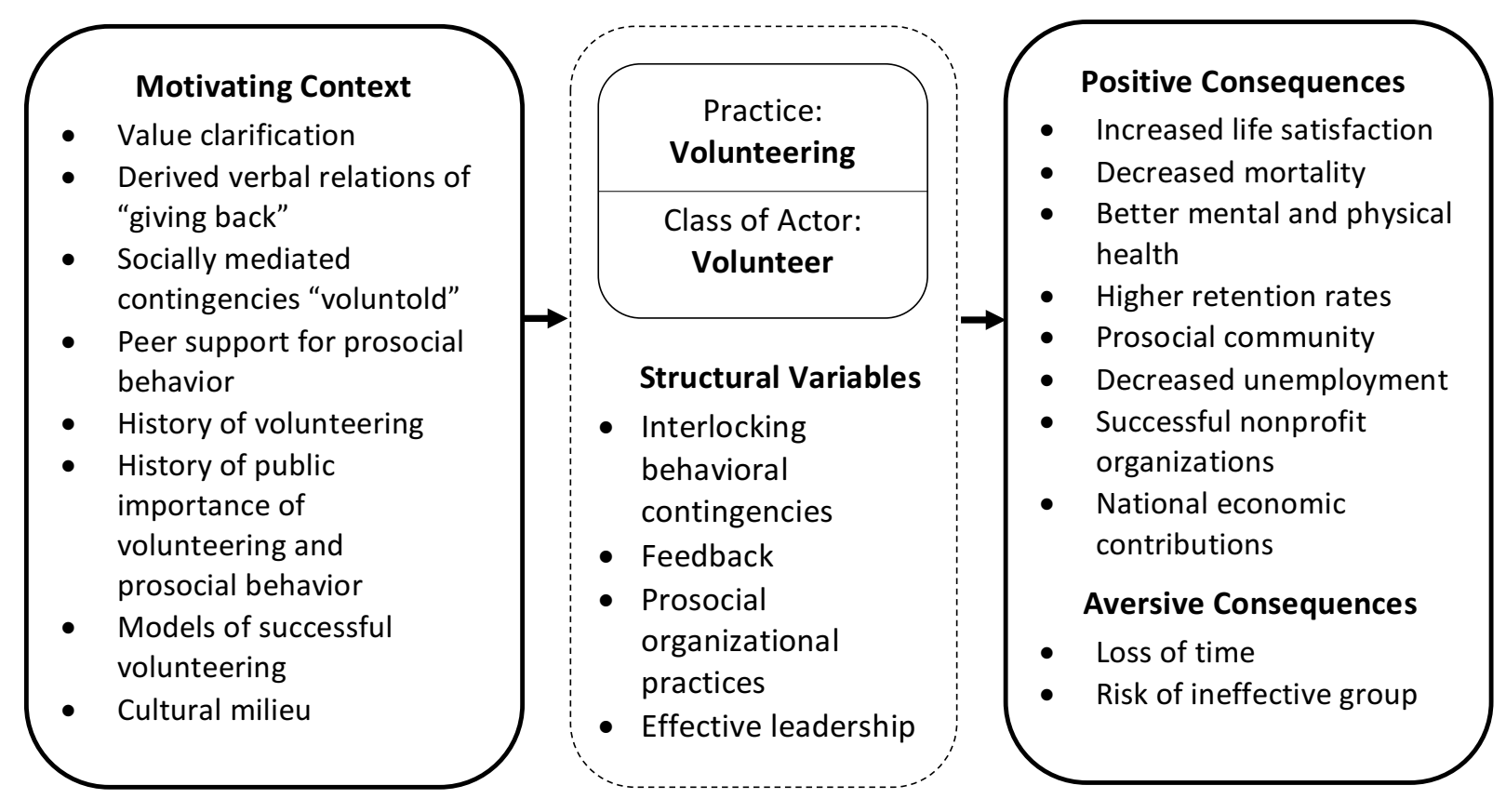

Figure 2: Variables involved in the successful practice of organizations recruiting, supporting, and retaining volunteers. To encourage increased volunteer behavior, motivating contexts could be manipulated, organizational infrastructure refined, and increased promotion of positive consequences.

practices that form with a nonviolent activist group, groups of volunteers create a social network that can develop cultural practices that influence volunteer participation. Volunteers, and similarly those involved in collective nonviolent efforts, most often behave with respect to immediate issues rather than the ultimate outcome (Mattaini, 2003). Houmanfar and colleagues (2015) suggest shifting the emphasis to establishing organizational practices that support and maintain prosocial behavior and eliminate aversive conditions. Leadership practice is essential in shifting organizational values through communication, motivating the workforce, and ensuring the necessary resources to do so (Houmanfar et al., 2015). When leadership cultivates a more reinforcing system, volunteers can then respond to immediate contingencies resulting in long-term benefits to the system and ultimately those served.

\section{Conclusion}

Investigating volunteer behavior and the conditions under which volunteers sustain their engagement within a system of volunteers aligns well with behavior analysis. While many contributors in various fields have developed models to predict prosocial behavior, there is still a need to consider the controlling variables that shape and maintain volunteering as a unique class of behavior within arranged organizational contingencies. The current paper has provided a conceptual account of the volunteer event, speculated potential relevant antecedents and consequences, and provided a suggested functional definition from a behavioral perspective. With a framework in place, behavior analysts are well poised to study volunteerism empirically. More 
behavioral research is needed to help identify the behavioral principles related to volunteerism and how to utilize the principles to better shape and maintain volunteer behavior.

There are numerous opportunities to design and implement empirical studies in the area of volunteerism both at the individual and systemic levels. At the individual level, replication and extension of the discounting work on altruism could prove helpful in identifying how contextual variables influence the likelihood of individuals to participate and maintain engagement in a volunteering activity. Much could be done in the assessment of volunteer behavior such as detailed descriptive analyses and functional analyses, which could then lead to new interventions for volunteer retention. At the systemic level, potential basic and applied work could be orchestrated to study volunteer activity within the context of a macrocontingency or a metacontingency. Various manipulations within a real or hypothetical organization may reveal important interrelations between hired and volunteer staff, or the necessary interlocking behavioral contingencies that cumulatively produce an aggregate product.

Studying volunteerism via basic, applied, correlational, or experimental means poses some legitimate barriers. When considering the unique issues of measuring volunteer activity, the limitations in the literature thus far become instantly understandable. For one, external validity in highly-controlled laboratory experiments is difficult to achieve. Producing predictably sustained volunteer activity in an analogue study is arguably different than in an applied setting with greater time delays and more salient competing contingencies. Given the difficulties, it may be a more efficient and effective approach to study volunteerism in applied settings, following the mainstream volunteerism studies. From an applied perspective, however, controlled experiments are also difficult. Feasibility often comes into question since many non-profit organizations are small in size, overworked, underpaid, and traditionally underequipped with proper technology to measure the target behavior. Additionally, the inability to pay competitively and excessive workloads result in challenges for retention ("2015 Nonprofit Employment Practices Survey Results", 2015). Perhaps, the best option for effective research in this area would be to work with an organization that not only has a history of success and sustainability within a tight financial market, but also values the collection and analysis of behavior patterns within its system.

If behavior analysts, specifically those interested in organizational behavior management and BSA, developed a behavioral perspective on volunteer behavior and how volunteers function within systems, the potential benefits could be limitless. Biglan (2014) argues that the significance and level of meaningful change of any social movement, which includes the behavior of volunteers, is contingent on the effectiveness of advocacy organizations to mobilize people to take action. There is clearly a societal need for the maintenance of volunteer activity, yet we know comparatively little on how to effectively sustain volunteer engagement.

In expanding analysis to the realm of volunteerism and non-profit agencies, the field of behavior analysis may find new opportunities to become more accessible to the public. Behavior science offers newly established interventions geared toward cultural change, and examines the conditions responsible for establishing lasting behavior change (Mattaini, 2006). Dissemination of behavior analytic principles, however, is a common concern among academics and practitioners alike (Freedman, 2015; Hayes \& Thomas, 2004; Hyten, 2009). The more we can produce research and programs for organizations that rely on volunteerism, the more likely non-behavior analytic populations will consume and appreciate behavior analytic work. By using behavior science to improve our understanding of volunteerism, the field of behavior analysis may potentially expose a new population to its pragmatic perspective. Dissemination of scientific principles is paramount 
to the field's survival; the more behavioral research proves to be necessary for solving complex social issues, the more likely behavior analysis will be demanded in the future.

As behavior analysis and behavioral systems analysis become more robust, behavior analysts are in a prime position to start tackling larger societal issues that to date have not been resolved in other disciplines. Volunteerism, viewed from both the individual and systemic levels, is one such area where behavior science could contribute substantially. The present paper showcased one such area in dire need of improvement: the significant proportion of children living in poverty who lose out on necessary educational and social supports. While organizations like BBBS contribute significantly to supporting and educating at-risk youth, unleashing the power of behavior science could lead to more rapid and focused societal interventions. If behavior scientists can develop the procedures and technologies needed by these integral institutions, our culture will be all the better for it.

\section{References}

2015 Nonprofit Employment Practices Survey Results. (2015). Washington, D.C.

“Altruism” (2016). Merriam Webster. Retrieved from http://www.merriam-webster.com/dictionary/altruism

Baer, D. M., Wolf, M. M. and Risley, T. R. (1968), Some current dimensions of applied behavior analysis. Journal of Applied Behavior Analysis, 1, 91-97. http://doi.org/10.1901/jaba.1968.1-91 Retrieved from https://www.ncbi.nlm.nih.gov/pmc/articles/PMC1310980/

Bandura, R. P., \& Lyons, P. R. (2012). Helping managers stimulate employee voluntary, helpful behavior. Industrial and Commercial Training, 44(2), 94-102. http://doi.org/10.1108/00197851211202939

Big impact--proven results. (2016). Retrieved February 29, 2016, from http://www.bbbs.org/site/c.9iILI3NGKhK6F/b.5961035/k.A153/Big impact8212proven results.htm

Biglan, A. (2003). Selection by consequences: one unifying principle for a transdisciplinary science of prevention. Prevention Science: The Official Journal of the Society for Prevention Research, 4(4), 213-32. Retrieved from http://www.ncbi.nlm.nih.gov/pubmed/14598995

Biglan, A. (2009). The role of advocacy organizations in reducing negative externalities. Journal of Organizational Behavior Management, 29(3), 215-230. http://doi.org/10.1080/01608060903092086

Biglan, A. (2015). The nurture effect: How the science of human behavior can improve our lives and our world. Oakland: New Harbinger Publications.

Biglan, A., \& Glenn, S. (2013). Toward prosocial behavior and environments: Behavioral and cultural contingencies in a public health framework. In G. J. Madden, W. V. Dube, T. D. Hackenberg, G. P. Hanley, \& K. A. Lattal (Eds.), APA Handbook of Behavior Analysis, Vol. 2: Translating Principles Into Practice (pp. 255-275). Washington, D.C.: American Pscyhological Association. http://doi.org/10.1037/13938-010

Boezeman, E. J., \& Ellemers, N. (2008). Volunteer recruitment: the role of organizational support and anticipated respect in non-volunteers' attraction to charitable volunteer organizations. The Journal of Applied Psychology, 93(5), 1013-26. http://doi.org/10.1037/0021-9010.93.5.1013

Brennan, M. A. (2007). Volunteerism and community development: A comparison of factors shaping volunteer behavior in Irish and American communities. The International Journal of Volunteer Administration, 24(4), $60-70$.

Brown, E., \& Ferris, J. M. (2007). Social capital and philanthropy: An analysis of the impact of social capital on individual giving and volunteering. Nonprofit and Voluntary Sector Quarterly, 36(1), 85-99. http://doi.org/10.1177/0899764006293178

Brown, S. L., Nesse, R. M., Vinokur, A. D., \& Smith, D. M. (2003). Providing social support may be more beneficial than receiving it: results from a prospective study of mortality. Psychological Science, 14(4), 320-7. Retrieved from http://www.ncbi.nlm.nih.gov/pubmed/12807404

Burkart, J. M., Fehr, E., Efferson, C., \& van Schaik, C. P. (2007). Other-regarding preferences in a non-human primate: Common marmosets provision food altruistically. Proceedings of the National Academy of Sciences of the United States of America, 104(50), 19762-19766. http://doi.org/10.1073/pnas.0710310104

Clary, E. G., Snyder, M., Ridge, R. D., Copeland, J., Stukas, a a, Haugen, J., \& Miene, P. (1998). Understanding and assessing the motivations of volunteers: a functional approach. Journal of Personality and Social Psychology, 74(6), 1516-30. Retrieved from http://www.ncbi.nlm.nih.gov/pubmed/9654757 


\section{ORGANIZED COOPERATION}

Clutton-Brock, T. (2009). Cooperation between non-kin in animal societies. Nature, 462(7269), 51-7. http://doi.org/10.1038/nature08366

Cornelis, I., Van Hiel, A., \& De Cremer, D. (2013). Volunteer work in youth organizations: predicting distinct aspects of volunteering behavior from self- and other-oriented motives. Journal of Applied Social Psychology, 43(2), 456-466. http://doi.org/10.1111/j.1559-1816.2013.01029.x

Dickinson, A. M. (2000). The historical roots of organizational behavior management in the private sector: The 1950s-1980s. Journal of Organizational Behavior Management, 20(3/4), 9-59.

Eisner, D., Grimm, R., \& Maynard, S. (2009). The new volunteer workforce. Stanford Social Innovation Review, $32-$ 37(Winter), 32-37. Retrieved from http://www.volunteeringinamerica.gov/assets/resources/thenewvolunteerworkforce.pdf

Farmer, S. M., \& Fedor, D. B. (1999). Volunteer participation and withdrawal. Nonprofit Management and Leadership, 9(4), 349-368. http://doi.org/10.1002/nml.9402

Federal Intergency Forum on Child and Family Statistics. (2015). America's children: Key national indicators of well-being. Washington, DC: U.S. Government Printing Office.

Finkelstein, M. a. (2008). Volunteer satisfaction and volunteer action: A functional approach. Social Behavior and Personality: An International Journal, 36(1), 9-18. http://doi.org/10.2224/sbp.2008.36.1.9

Freedman, D. H. (2015). Improving public perception of behavior analysis. The Behavior Analyst, 1-7. http://doi.org/10.1007/s40614-015-0045-2

Ganesh, S., \& McAllum, K. (2011). Volunteering and professionalization: Trends in tension? Management Communication Quarterly, 26(1), 152-158. http://doi.org/10.1177/0893318911423762

Govekar, P. L., \& Govekar, M. a. (2002). Using economic theory and research to better understand volunteer behavior. Nonprofit Management and Leadership, 13(1), 33-48. http://doi.org/10.1002/nml.13104

Gross, K., \& Page, A. (2013). Charities and their volunteers: Working together to help the publci. Internal Revenue Service. Retrieved from https://www.stayexempt.irs.gov/Resource-Library/Charities-and-Volunteers

Guerin, B. (1994). Analyzing social behavior: Behavior analysis and the social sciences. Reno, NV: Context Press.

Han, C.-K., \& Hong, S.-I. (2012). Trajectories of Volunteering and Self-Esteem in Later Life: Does Wealth Matter? Research on Aging, 35(5), 571-590. http://doi.org/10.1177/0164027512449472

Harlow, R., \& Cantor, N. (1996). Still participating after all these years: A study of life task participation in later life. Journal of Personality and Social Psychology, 71(6), 1235-1249. Retrieved from http://psycnet.apa.org/journals/psp/71/6/1235/

Hayes, L. J., \& Thomas, J. L. (2004). On the practical value system building for behavior science. The Behavior Analyst Today, 5(3), 284-289.

Hayes, S. C. (2004). Acceptance and commitment therapy, relational frame theory, and the third wave of behavioral and cognitive therapies. Behavior Therapy, 35, 639-665.

Hayes, S. C., \& Brownstein, A. J. (1986). Mentalism, behavior-behavior relations, and a behavior-analytic view of the purposes of science. The Behavior Analyst, 9(2), 175-190. http://doi.org/10.4324/9781315745138

Hayes, S. C., Bunting, K., Herbst, S., Bond, F. W., \& Barnes-Holmes, D. (2006). Expanding the scope of organizational behavior management : Relational frame theory and the experimental analysis of complex human behavior. Journal of Organizational Behavior Management, 26(1/2), 1-23. http://doi.org/10.1300/J075v26n01

Hayes, S. C., Gifford, E. V, \& Hayes, G. J. (1998). Moral behavior and the development of verbal regulation. The Behavior Analyst / MABA, 21(2), 253-79. Retrieved from http://www.pubmedcentral.nih.gov/articlerender.fcgi?artid=2731399\&tool=pmcentrez\&rendertype=abstract

Hayes, S. C., \& Sanford, B. T. (2014). Cooperation came first: Evolution and human cognition. Journal of the Experimental Analysis of Behavior, 101(1), 112-129. http://doi.org/10.1002/jeab.64

Hayes, S., Hayes, L., \& Reese, H. (1988). Finding the philosophical core: A review of Steven C. Pepper's World Hypotheses: A study in evidence. Journal of the Experimental Analysis of Behavior, 50(1), 97-111. Retrieved from http://onlinelibrary.wiley.com/doi/10.1901/jeab.1988.50-97/abstract

Herbst, S. A., \& Houmanfar, R. (2009). Psychological approaches to values in organizations and organizational behavior management. Journal of Organizational Behavior Management, 29(1), 47-68. http://doi.org/10.1080/01608060802714210

Holland, J. G. (1978). Behaviorism: part of the problem or part of the solution. Journal of Applied Behavior Analysis, 11(1), 163-74. http://doi.org/10.1901/jaba.1978.11-163 


\section{BRAYKO, HOUMANFAR, \& GHEZZI}

Houmanfar, R. A., Alavosius, M. P., Morford, Z. H., Herbst, S. A., \& Reimer, D. (2015). Functions of organizational leaders in cultural change: Financial and social well-being. Journal of Organizational Behavior Management, 35(1-2), 4-27. http://doi.org/10.1080/01608061.2015.1035827

Houmanfar, R., \& Johnson, R. (2004). Organization implications of gossip and rumour. Journal of Organizational Behavior Management, 23(2-3), 117-138. http://doi.org/10.1300/J075v23n02

Houmanfar, R., \& Rodrigues, N. J. (2006, March 16). The metacontingency and the behavioral contingency: Points of contact and departure. Behavior and Social Issues. http://dx.doi.org/10.5210/bsi.v15i1.342

Houmanfar, R., Rodrigues, N. J., \& Ward, T. A. (2010). Emergence and metacontingency: Points of contact and departure. Behavior \& Social Issues, 19, 78-103. http://dx.doi.org/10.5210/bsi.v19i0.3065

Houmanfar, R., \& Ward, T. (2012, June). Value clarification \& perspective taking in effective organizational change processes. Paper presentation at the Proceedings of the 8th International Conference for the Association for Advancement of Radical Behavior Analysis, Rome, Italy.

Howard, V. J., \& Digennaro Reed, F. D. (2014). Training shelter volunteers to teach dog compliance. Journal of Applied Behavior Analysis, 47(2), 344-359. http://doi.org/10.1002/jaba.120

Howard, V. J., \& Digennaro Reed, F. D. (2015). An evaluation of training procedures for animal shelter volunteers. Journal of Organizational Behavior Management, 35(3-4), 296-320. http://doi.org/10.1080/01608061.2015.1093052

Hyde, M. K., Dunn, J., Scuffham, P. A., \& Chambers, S. K. (2014). A systematic review of episodic volunteering in public health and other contexts. BMC Public Health, 14(1), 992. http://doi.org/10.1186/1471-2458-14-992

Hyten, C. (2009). Strengthening the focus on business results: The need for systems approaches in organizational behavior management. Journal of Organizational Behavior Management, 29(2), 87-107. http://doi.org/10.1080/01608060902874526

Johnson, R. A., Houmanfar, R., \& Smith, G. S. (2010). The effect of implicit and explicit rules on customer greeting and productivity in a retail organization. Journal of Organizational Behavior Management, 30(1), 38-48. http://doi.org/10.1080/01608060903529731

Jones, B. a, \& Rachlin, H. (2009). Delay, probability, and social discounting in a public goods game. Journal of the Experimental Analysis of Behavior, 91(1), 61-73. http://doi.org/10.1901/jeab.2009.91-61

Kawashima-Ginsberg, K., Lim, C., \& Levine, P. (2012). Civic health and unemployment II: The case builds. Washington, D.C. Retrieved from http://ncdd.org/rc/item/7259

Keller, F., S., Schoenfeld, \& N., W. (1950). Principles of psychology: A systematic text in the science of behavior. New York: Appleton-Century-Crofts.

Lee, Y. J., \& Brudney, J. L. (2012). Participation in formal and informal volunteering: Implications for volunteer recruitment. Nonprofit Management and Leadership, 23(2), 159-180. http://doi.org/10.1002/nml.21060

Liao-Troth, M. a. (2005). Are they here for the long haul? The effects of functional motives and personality factors on the psychological contracts of volunteers. Nonprofit and Voluntary Sector Quarterly, 34(4), 510-530. http://doi.org/10.1177/0899764005279513

Locey, M. L., Jones, B. a, \& Rachlin, H. (2011). Real and hypothetical rewards. Judgment and Decision Making, $6(6), 552-564$. Retrieved from http://www.pubmedcentral.nih.gov/articlerender.fcgi?artid=3348706\&tool=pmcentrez\&rendertype=abstract

Locey, M., Safin, V., \& Rachlin, H. (2013). Social discounting and the prisoner's dilemma game. Journal of the Experimental Analysis of Behavior, 99(1), 85-97. http://doi.org/10.1002/jeab.3.Social

Malott, M. E., \& Martinez, W. S. (2006). Addressing organizational complexity: A behavioural systems analysis application to higher education. International Journal of Psychology, 41(6), 559-570. http://doi.org/10.1080/00207590500492773

Malott, M., \& Glenn, S. (2006). Targets of intervention in cultural and behavioral change. Behavior \& Social Issues, 56, 31-56. http://dx.doi.org/10.5210/bsi.v15i1.344

Malott, R. W. (1988). Rule-governed behavior and behavioral anthropology. The Behavior Analyst / MABA, 11(2), 181-203. Retrieved from http://www.pubmedcentral.nih.gov/articlerender.fcgi?artid=2741954\&tool=pmcentrez\&rendertype $=$ abstract

Mattaini, M. (2013). Strategic nonviolent power: The science of Satyagraha. Edmonton: AU Press, Athabasca University. Retrieved from

http://books.google.com/books?hl=en\&lr=\&id=RfWhAQAAQBAJ\&oi=fnd\&pg=PP13\&dq=Strategic + Nonvio lent+Power: + The + Science + of + Satyagraha\&ots=3qL5aFgFEw\&sig=CPdm6ypYbK9WyJlzatfe0Jtnc78

Mattaini, M. A. (2003). Constructing nonviolent alternatives to collective violence: A scientific strategy. Behavior and Social Issues, 12, 148-163. http://dx.doi.org/10.5210/bsi.v12i2.41 


\section{ORGANIZED COOPERATION}

Mattaini, M. A., \& Aspholm, R. (2015). Contributions of behavioral systems science to leadership for a new progressive movement. The Behavior Analyst. http://doi.org/10.1007/s40614-015-0043-4

McBride, a. M., \& Lee, Y. (2011). Institutional predictors of volunteer retention: The case of AmeriCorps National Service. Administration \& Society, 44(3), 343-366. http://doi.org/10.1177/0095399711413729

McKeever, B. S. (2015). The nonprofit sector in brief 2015: Public charities, giving, and volunteers. Washington, D.C.: Urban Institute.

Mowen, J. C., \& Sujan, H. (2005). Volunteer behavior: A hierarchical model approach for investigating its trait and functional motive antecedents. Journal of Consumer Psychology, 15(2), 170-182. Retrieved from http://wx2mz2qh41.search.serialssolutions.com/?ctx ver=Z39.88-2004\&ctx enc=info:ofi/enc:UTF8\&rfr id=info:sid/summon.serialssolutions.com\&rft val fmt=info:ofi/fmt:kev:mtx:journal\&rft.genre=article\& rft.atitle $=$ Volunteer+Behavior: + A + Hierarchical + Mode

Nenga, S. K. (2012). Not the community, but a community: Transforming youth into citizens through volunteer work. Journal of Youth Studies, 15(8), 1063-1077. http://doi.org/10.1080/13676261.2012.697135

Nichols, G. (2012). The psychological contract of volunteers: A new research agenda. VOLUNTAS: International Journal of Voluntary and Nonprofit Organizations, 24(4), 986-1005. http://doi.org/10.1007/s11266-012-9294$\underline{9}$

Post, S. G. (2005). Altuism, happiness, and health: it's good to be good. International Journal of Behavioral Medicine, 12(2), 66-77. http://doi.org/10.1207/s15327558ijbm1202 4

Rachlin, H. (2002). Altruism and selfishness. The Behavioral and Brain Sciences, 25, 239-250; discussion 251-296. http://doi.org/10.1017/S0140525X02000055

Rachlin, H., \& Jones, B. a. (2008). Altruism among relatives and non-relatives. Behavioural Processes, $79(2), 120$ 3. http://doi.org/10.1016/j.beproc.2008.06.002

Rachlin, H., \& Locey, M. (2011). A behavioral analysis of altruism. Behavioural Processes, 87(1), 25-33. http://doi.org/10.1016/j.beproc.2010.12.004

Randle, M., \& Dolnicar, S. (2011). Self-congruity and volunteering: a multi-organisation comparison. European Journal of Marketing, 45(5), 739-758. http://doi.org/10.1108/03090561111120019

Robbins, T., Stagman, S., \& Smith, S. (2012). Young children at risk: National and state prevalence of risk factors. Retrieved March 12, 2016, from http://www.nccp.org/publications/pub 1073.html

Selected findings from PISA 2012. (n.d.) Retrieved from https://nces.ed.gov/surveys/pisa/pisa2012/pisa2012highlights 1.asp

Shye, S. (2009). The motivation to volunteer: A systemic quality of life theory. Social Indicators Research, 98(2), 183-200. http://doi.org/10.1007/s11205-009-9545-3

Skinner, B. F. (1965). Science and Human Behavior. New York: The Free Press.

Snyder, M., \& Omoto, a. (2008). Volunteerism: Social issues perspectives and social policy implications. Social Issues and Policy Review, 2(1), 1-36. http://doi.org/10.1111/j.1751-2409.2008.00009.x

Soreth, M. (2011). The False dichotomy of morality and self-interest as determinants of action: Facilitating intervention against genocide. Behavior and Social Issues, 20, 32-43. http://doi.org/10.5210/bsi.v20i0.2468

Starnes, B. J., \& Wymer Jr, W. W. (2000). Demographics, personality traits, roles, motivations, and attrition rates of hospice volunteers. Journal of Nonprofit \& Public Sector Marketing, 7(2), 61-76. http://doi.org/10.1300/J054v07n02 06

State of the sector surveys. (2015). Retrieved March 12, 2016, from http://www.nonprofitfinancefund.org/state-ofthe-sector-surveys

Steele, D., \& Hayes, S. C. (1991). Stimulus equivalence and arbitrarily applicable relational responding. Journal of the Experimental Analysis of Behavior, 56(3), 519-555.

Stürmer, S., Snyder, M., Kropp, A., \& Siem, B. (2006). Empathy-motivated helping: The moderating role of group membership. Personality and Social Psychology Bulletin, 32(7), 943-956. http://doi.org/10.1177/0146167206287363

Stürmer, S., Snyder, M., \& Omoto, A. M. (2005). Prosocial emotions and helping: the moderating role of group membership. Journal of Personality and Social Psychology, 88(3), 532-46. http://doi.org/10.1037/0022$\underline{3514.88 .3 .532}$

The benefits of mentoring. (2012). Retrieved from http://www.bbbsmi.org/site/c.7pLFLSPzELUH/b.7731103/k.80E0/The Benefits of Mentoring.htm

The Value of Volunteer Time. (2016). Retrieved from http://independentsector.org/volunteer time

Thoits, P., \& Hewitt, L. (2001). Volunteer work and well-being. Journal of Health and Social Behavior, 42(2), 115131. http://doi.org/10.2307/3090173 


\section{BRAYKO, HOUMANFAR, \& GHEZZI}

Thompson, T., \& Lubinski, D. (1986). Units of analysis and kinetic structure of behavioral repertoires. Journal of Experimental Analysis of Behavior, 46(2), 219-242. Retrieved from http://onlinelibrary.wiley.com/doi/10.1901/jeab.1986.46-219/abstract

Tomasello, M., \& Vaish, A. (2013). Origins of human cooperation and morality. Annual Review of Psychology, 64, 231-255. http://doi.org/10.1146/annurev-psych-113011-143812

Vantilborgh, T., Bidee, J., Pepermans, R., Willems, J., Huybrechts, G., \& Jegers, M. (2011). Volunteers' psychological contracts: Extending traditional views. Nonprofit and Voluntary Sector Quarterly, 41(6), 10721091. http://doi.org/10.1177/0899764011427598

Volunteer Retention. (2007). Corporation for national \& community service. Washington, D.C. Retrieved from http://www.energizeinc.com/art/npret.html

Volunteering and civic engagement in the United States. (2014). Corporation for National \& Community Service. Washington, D.C. Retrieved from http://2013.volunteeringinamerica.gov/national

Volunteering in 2014. (2015). Bureau of Labor Statistics. Retrieved from http://www.bls.gov/opub/ted/2015/volunteering-in-2014.htm

Wymer Jr, W. W., \& Starnes, B. J. (2001). Conceptual foundations and practical guidelines for recruiting volunteers to serve in local nonprofit organizations : Part I. Journal of Nonprofit \& Public Sector Marketing, 9(1-2), 6396.

Yi, R., Charlton, S., Porter, C., Carter, A., \& Bickel, W. (2011). Future altruism: Social discounting of delayed rewards. Behavioural Processes, 86(1), 160-163. http://doi.org/10.1016/j.beproc.2010.09.003.Future 